\title{
Cardiovascular disease in HIV patients: recent advances in predicting and managing risk
}

\section{Padraig McGettrick, Patrick WG Mallon \& Caroline A Sabin}

To cite this article: Padraig McGettrick, Patrick WG Mallon \& Caroline A Sabin (2020):

Cardiovascular disease in HIV patients: recent advances in predicting and managing risk, Expert Review of Anti-infective Therapy, DOI: 10.1080/14787210.2020.1757430

To link to this article: https://doi.org/10.1080/14787210.2020.1757430

Accepted author version posted online: 18

Apr 2020.

Submit your article to this journal $₫$

山 Article views: 5

Q View related articles $\widetilde{ }$

View Crossmark data \lceil 
Publisher: Taylor \& Francis \& Informa UK Limited, trading as Taylor \& Francis Group

Journal: Expert Review of Anti-infective Therapy

DOI: $10.1080 / 14787210.2020 .1757430$

Article type: Review

Cardiovascular disease in HIV patients: recent advances in predicting and managing risk

Padraig McGettrick ${ }^{1}$, Patrick WG Mallon ${ }^{1,2}$, Caroline A Sabin ${ }^{3}$

${ }^{1}$ Centre for Experimental Pathogen Host: Research, UCD School of Medicine, Dublin, Ireland

${ }^{2}$ Department of Infectious Diseases, St. Vincent's University Hospital, Dublin, Ireland

${ }^{3}$ Centre for Clinical Research, Epidemiology, Modelling and Evaluation, Institute for Global Health, University College London, London, UK

*Corresponding author:

Padraig McGettrick

Centre for Experimental Pathogen Host: Research,

UCD School of Medicine, Dublin, Ireland

Email: padraig.mcgettrick@ucd.ie 


\section{Abstract}

Introduction: Cardiovascular disease (CVD) is one of the leading causes of mortality in virally suppressed people living with HIV (PLWH) and with an ageing population, is likely to become one of the leading challenges in maintaining good health outcomes in HIV infection. However, factors driving risk of CVD in PLWH are multiple and may be different from those of the general population, raising challenges to predicting and managing CVD risk in this population.

Areas covered: In this review, we examine the relevant data regarding CVD in HIV infection including that on CVD prevalence, pathogenesis and contributing factors. We review the data regarding CVD risk prediction in PLWH and summarise factors, both general and HIV specific, that may influence CVD risk in this population. And finally we discuss appropriate management of CVD risk in PLWH and explore potential therapeutic pathways which may mitigate CVD risk in the future in this population.

Expert opinion: Following a comprehensive review of CVD risk in PLWH, we give our opinion on the primary issues in risk prediction and management of CVD in HIV infected individuals and discuss the future direction of CVD management in this population.

Keywords: Anti-retroviral therapy (ART), Cardiovascular disease, CVD Prevention, CVD Management, HIV, Inflammation, Risk Prediction 


\section{Introduction}

With the success of antiretroviral therapy (ART) in achieving HIV viral suppression and arresting CD4+ T-cell decline with subsequently reduced AIDS-related morbidity and mortality in the treated population of people living with HIV (PLWH), focus has turned to non-AIDS-related illness as the major threat to the overall health of PLWH on effective ART. Cardiovascular disease (CVD) is now a leading cause of death in people with treated HIV infection and the incidence of this is likely to continue to increase as the global population of PLWH ages. However, factors driving risk of cardiovascular disease in PLWH are multiple and may be different from those of the general population, raising challenges to mitigating CVD risk in this population. In this review we summarise the relevant data in the field and describe the primary factors which should be considered when predicting and managing CVD risk in PLWH.

\section{The prevalence of CVD in PLWH}

CVD has long been recognised as a significant contributor to morbidity and mortality in PLWH, with early cohort studies reporting a higher prevalence and/or younger age at onset of CVD in this group (1-4). A recent meta-analysis including 793,635 participants from 73 studies, of predominantly American and European populations, estimated a relative risk (RR) of CVD in PLWH of 2.16 (95\% confidence interval [CI], 1.68-2.77) compared to people without HIV; whilst high, this analysis did not fully adjust for important cofounders such as smoking and HIV treatment status due to incomplete data (5). Other cohorts have reported similar findings, including the Veterans Ageing Cohort Study (VACS) comprising over 82,000 participants with and without HIV, in which HIV infection was associated with an increased risk of acute myocardial infarction (AMI), even after adjustment for traditional CVD risk 
factors (hazard ratio [HR] 1.72 [95\% Cl 1.49-1.97]) (6). In a further analysis of this cohort, stratified for the number of CVD risk factors present in each individual, PLWH had higher rates of AMI than uninfected individuals at each level of stratification (3). However, fewer than half of PLWH in this study had initiated ART and adjustment for viral suppression somewhat weakened the association (HR 1.39 [1.17-1.66]).

Within the Kaiser Permanente healthcare database of over 22,000 PLWH, matched with demographically-similar uninfected controls, AMI rates were again found to be higher in PLWH (RR 1.4 [1.3-1.6]). In this analysis, lower nadir CD4+ T-cell count was the sole HIVspecific factor associated with the increased risk, with PLWH with a recent CD4+ T-cell count $>500$ cells $/ \mathrm{ml}$ having a similar risk to that of their uninfected counterparts (4). Caution is needed when interpreting results from cohort studies however as incomplete data may limit adjustment for confounders, and definitions of CVD vary and may fail to capture important subtleties of clinical diagnosis, such as the difference between type 1 (atherothrombotic event) and type 2 (ischemia secondary to increased demand or reduced supply, often in absence of significant atherosclerotic disease) AMI.

Cross sectional studies examining surrogate markers of CVD such as carotid intima thickness, pulse wave velocity, coronary artery calcium (CAC) score and CT coronary angiography (CTCA), have attempted to compare subclinical CVD prevalence between PLWH and the general population, with mixed results. In 2010, Lo et. Al. reported higher prevalence of total coronary atherosclerotic disease, median plaque volume and Agatston CAC score in asymptomatic men with HIV (median age: 46 years) compared to uninfected controls with similar Framingham risk scores and smoking prevalence (7). In this relatively 
small study $(n=110)$, higher plaque burden correlated with increased Framingham risk score (Spermans correlation coefficient $(\mathrm{Rho})=0.43, \mathrm{p}<0.001$ ), lipid concentrations (total cholesterol; Rho $=0.35, p=0.002, \mathrm{LDL} ; \mathrm{rho}=0.32, \mathrm{p}=0.005)$ and lower $\mathrm{CD} 4+\mathrm{CD} 8+\mathrm{T}$-cell ratio (rho $=-0.25, p=0.03$ ) with duration of HIV infection being associated with plaque volume in multivariate models.

The Multicenter AIDS Cohort Study (MACS) also examined CVD, including CTCA, in 759 men with and without HIV. After excluding men with a prior history of percutaneous coronary intervention or cardiac surgery, HIV infection was associated with a CAC score $>0$ but the association was attenuated after adjustment for other CAD risk factors (8). However HIV infection remained associated with presence of overall plaque and non-calcified plaque even after adjustment.

In contrast, Lai et. al. reported a non-significant association between HIV infection and subclinical CVD in a large ( $n=1429$ ) observational study of African American men and women undergoing CTCA. Chronic cocaine use was most strongly associated with subclinical CVD, the prevalence of which was over represented in the group without HIV infection (9). The Swiss HIV Cohort study reported no difference in CAC score and presence of atherosclerotic plaque between asymptomatic PLWH $(n=428)$ and HIV-negative controls $(n=276)$ with similar Framingham risk scores undergoing CTCA for clinical indications, although PLWH were significantly younger than the HIV-negative controls. PLWH had less calcified plaque and were less likely to have severe disease after adjustment for other CVD risk factors including age, diabetes and dyslipidemia (10). 
Whilst results from these studies were inconsistent, subclinical CVD may not be the best predictor of clinical CVD events. Together the accumulated data from cohort studies would suggest an increased risk of clinical CVD events in PLWH but the relative contributions of traditional cardiovascular risk factors versus HIV- and ART-specific factors are, as yet, unclear. This complicates both the prediction of CVD risk in PLWH and the development of strategies to reduce risk in this group with further well-designed studies needed to fully examine and explore the pathogenesis of CVD in PLWH.

\section{Role of Antiretroviral therapy in CVD Risk}

Our understanding of the role of ART in CVD risk has evolved over recent years. The Data collection on Adverse events of anti-HIV Drugs (D:A:D) study first reported an increased risk of $\mathrm{MI}$ in those with longer exposure to ART in 2003 , with a $26 \%$ relative increase in AMI per additional year of exposure (11). The study population was heavily exposed to protease inhibitors (PI) with further studies finding an association with specific PI drugs, associations which were only partially explained by worsening metabolic parameters on initiation of these drugs (12). With the development of newer, more metabolically-neutral ART, the CVD risk associated with treatment was thought to be reduced. However more recently, darunavir, a member of the PI drug class with considerably less impact on lipid parameters than its predecessors and a drug which is still widely used in clinical practice, has also been associated with an increased risk of $\mathrm{MI}(13)$. This association again persisted even after adjustment for lipid concentrations, warranting further examination of the impact of PIs on cardiovascular health and the mechanistic processes driving this association. 
Abacavir, a nucleoside reverse transcriptase inhibitor (NRTI), has also been associated with MI risk in multiple observational studies, leading to the recommendation of alternative drug options in individuals with established CVD or multiple CVD risk factors (14). However, an association between $A B C$ use and CVD was not observed in some randomised controlled trials (RCTs) and meta-analyses. Despite consistent mechanistic data, including from randomized trials, suggesting disruption of the platelet endothelial interface as an explanation for how abacavir may reversibly alter risk of $\operatorname{AMI}(15,16)$, the association remains a subject of continued debate (17).

Dyslipidemia has long been associated with HIV infection with both viral and treatment effects on peripheral lipid concentrations. First generation Pls such as indinavir and amprenavir, although not currently recommended in treatment guidelines, affect serum lipid concentrations, with cumulative exposure associated with additional CVD risk (18). The non-nucleoside reverse transcriptase inhibitor efavirenz (EFV) increases total cholesterol, LDL and HDL levels when compared to a regimen containing an integrase strand transfer inhibitor (INSTI), a new class of ART with seemingly less impact on overall lipid concentrations $(19,20)$. Conversely the NRTI tenofovir disoproxil fumarate (TDF), widely used in clinical practice, appears to have beneficial effects on overall lipid concentrations. However with tenofovir alafenamide (TAF) replacing TDF in many ART regimens resulting in lower systemic exposure to tenofovir and subsequently its lipid-lowering effects, a deterioration in lipid concentrations has been reported in some cohorts (21), the clinical relevance of which has yet to be determined. 
More recently significant weight gain has been reported in observational studies of people initiating and, indeed, switching to regimens containing INSTI and TAF. In a recent pooled analysis of 8 RCTs of around 5,000 people initiating ART between 2003 and 2019, those commencing an INSTI-containing regimen were more likely to have significant weight gain at 96 weeks with the greatest weight gain associated with bictegravir and dolutegravir (DTG) compared to elvitegravir (22). Among the NRTIs, TAF was associated most strongly with weight gain with a mean increase of $4.25 \mathrm{~kg}$ [95\% Cl 3.94-4.56] compared to $2.07 \mathrm{~kg}$ in those receiving TDF [95\% Cl 1.84-2.30]. Weight gain was seen most commonly among black women, and although the study investigators did not see any significant difference between drugs in metabolic parameters such as fasting glucose levels, the duration of follow-up (96 weeks) was likely too short to reasonably address this concern. Similarly in a recent RCT in a South African population of ART-naïve participants initiating treatment, the combination of TAF/emtricitabine (FTC) and DTG was associated with significantly greater weight gain at 48 weeks compared to either or TDF/FTC/EFV or the combination of DTG with TDF/FTC (23). The mechanism behind the weight gain associated with these agents is currently unclear but deserves more attention, especially in the global setting where these agents are often recommended as first-line ART options. Although direct links between obesity and cardiovascular disease are inconsistent, as obesity is associated with development of metabolic abnormalities such as insulin resistance and hypertension, these may indirectly contribute to increased risk of CVD.

\section{Overall benefit of ART and viral suppression on reducing CVD risk}

While specific ART drugs/classes have been associated with CVD and deterioration in metabolic parameters, these concerns are clearly outweighed by the beneficial effects of 
ART and viral suppression on reducing inflammation and overall risk of CVD. Frieberg demonstrated a reduction in risk of MI with suppression of HIV RNA to $<500$ copies/ml in the VACS cohort, with the HR dropping from 1.48 [1.27-1.72] in the overall cohort to 1.39 [1.17-1.66] in a sensitivity analysis of those virally suppressed. The Strategies for Management of AntiretRoviral Therapy (SMART) study reported an increased risk of CVD events with interruption of antiretroviral therapy compared to continuous ART (24), while the START (Strategic Timing of ART) trial, which examined immediate versus delayed ART initiation (24), reported reduced CVD events in those who initiated ART immediately compared to those who deferred ART (HR 0.84 [0.39-1.81]) (25). Although the early termination of the START study limited the statistical power of this analysis, the overall finding of a 39\% reduction in serious non-AIDS events including CVD in the immediate ART arm highlighted the benefit of ART, despite the risk and metabolic derangements associated with some drugs.

Reports of increased CVD hospitalisations in HIV 'elite' controllers, individuals who maintain persistently low or undetectable levels of HIV viremia in the absence of ART, have questioned whether this minority of PLWH would also benefit from ART (26). Despite HIV suppression in the absence of ART in this subgroup, studies have demonstrated increased inflammation, particularly T cell activation in elite controllers, in addition to worse surrogate measures of CVD compared to PLWH on ART (27-30). However, the limited clinical data available is conflicting regarding the CVD risk in this small subgroup with potential confounders such as Hepatitis C virus co-infection and limited access to healthcare suggested as other possible explanations for these initial observations (31-33). Further 
clinical studies in this group are needed and the role of ART in management of these individuals remains controversial.

With the wider use of ART at all CD4+ T-cell counts, the introduction of newer ART classes with less deleterious effects on metabolic indices and a move away from PIs as first-line treatment, we appear to be seeing improvements in CVD mortality rates. The D:A:D study reported an age standardised drop in CVD mortality from 2.0/1000 persons in 1999-2000 to $0.7 / 1000$ in $2010-2011$ (34), with other cohorts reporting similar findings $(35,36)$. The reduction in CVD events in the D:A:D analysis was not solely explained by improved viral suppression rates, as an almost $50 \%$ reduction was also seen in the subgroup of those who were virally suppressed in both time periods. Viral suppression and avoidance of medications known to worsen traditional CVD risk factors are undoubtedly beneficial, however a growing awareness of CVD risk among HIV clinicians, particularly with respect to primary prevention and screening, is also likely contributing, with the reduction in CVD mortality being mirrored by an increase in statin use (37). Whether this reduction will also be seen in sub-Saharan Africa, a region estimated to have the highest burden of HIV-related CVD and where non-PI based ART is currently being rolled-out but where primary prevention strategies are less well developed, remains to be seen.

\section{CVD Risk Prediction in HIV}

\subsection{CVD risk Algorithms}

Estimation of CVD risk, using CVD risk equations based on traditional CVD risk factors, form the basis of primary preventative strategies for CVD in the general population. However their accuracy in predicting CVD in PLWH has been questioned. Numerous studies (table 2) 
have reported an underestimation, and some an overestimation, of observed risk of coronary heart disease (CHD) and CVD in PLWH using equations commonly used in the general population, such as the Framingham and Atherosclerotic Cardiovascular Disease (ASCVD) risk algorithms (38-41). The inadequacies of these scores and an awareness of other potential factors driving CVD risk in HIV infection such as ART, led to the D:A:D study developing their own risk prediction model (42). While the D:A:D score, which incorporates traditional risk factors in addition to HIV specific factors such as exposure to historical PIs and current use of abacavir, exhibited similar discriminatory ability to the Framingham score, it displayed distinctly improved calibration (mean ratio of the predicted to-observed number of events was $0.97,0.96$ and 0.95 for the $\mathrm{MI}, \mathrm{CHD}$ and CVD endpoints, respectively, compared with $1.14,1.35$ and 1.51 , respectively, for the Framingham risk equation).

Due to the relatively low number of CVD events in younger populations of PLWH, numerous cohort studies have also examined the utility of risk scores for prediction of subclinical CVD such as carotid intima media thickness (CIMT), again with the only consistent result being an underestimation of subclinical CVD in PLWH using these risk algorithms $(43,44)$. However, traditional risk factor scores were developed to predict clinical events rather than surrogate markers of CVD, making their use in these studies questionable.

Although comparisons of the various available risk equations have yielded inconsistent results with no single equation emerging as an optimal tool for the identification of PLWH at risk of CVD $(38,45-53)$, it is recommended that clinicians use one of these tools to assess CVD risk in all PLWH (54). With the publication of more recent guidance on risk factor management for CVD prevention with lowering of targets for LDL and blood pressure 
reduction in those at risk,-there may be an increased need for specific guidance for PLWH in the future.

\subsection{HIV specific markers for CVD prediction}

The CD4+:CD8+ T-cell ratio has emerged as a potential marker to identify treated PLWH at increased risk of developing comorbidities including CVD. A significant proportion of PLWH fail to normalize their CD4:CD8 ratio despite persistent viral suppression and adequate peripheral CD4+ T-cell recovery. A persistently inverted CD4+:CD8 ratio has been associated with an increased risk of comorbidities including CVD in numerous cohorts. In a retrospective analysis of over $2000 \mathrm{PLWH}$ who had experienced viral suppression on ART for at least 12 months, a lower CD4+:CD8+ ratio was independently associated with CVD events in participants less than 50 years of age (adjusted HR per 0.1 increase in ratio 0.83 [0.700.97]) (55). In a cross-sectional study of $914 \mathrm{PLWH}$, a CD4+:CD8+ ratio $<0.8$ was independently associated with CVD prevalence as defined by a CAC score $>100$ (56). Other studies have also demonstrated the ability of a lower $\mathrm{CD} 4+: \mathrm{CD} 8+$ ratio to predict progression of atherosclerotic disease as measured by $\operatorname{CIMT}(57,58)$. However, as only a minority of PLWH experience a normalization of their CD4+:CD8+ ratio after ART initiation, further research is needed to clarify the predictive role of the $C D 4+: C D 8+$ ratio for cardiovascular events in this population.

Inflammatory markers such as IL-6 have also been associated with subclinical atherosclerosis and non-AIDS events, including CVD, in PLWH $(25,59)$. More recently, in a case control study in PLWH, pre-event markers of IL-1 activity were predictive of first AMI (60). However whether the addition of inflammatory biomarkers to existing CVD risk 
algorithms would improve their accuracy and utility in the population of PLWH has not yet been examined and further work is needed to determine the clinical relevance of these associations in risk reduction strategies.

\section{Managing CVD risk in HIV}

Current evidence suggest inconsistencies in assessing CVD risk in the clinical setting, with numerous studies highlighting low levels of CVD risk assessment, with relatively low rates of achieving risk reduction targets within populations of PLWH (61-65). This may be changing however, with a move away from boosted regimens causing potential drug interactions that may have made clinicians reluctant to start concurrent medications, in addition to a greater awareness of CVD risk attributable to HIV infection.

\subsection{Statin use to reduce CVD risk}

Apart from the obvious beneficial effects of lowering lipids, the pleotropic effects of statins on atherosclerotic plaque stability and their potential anti-inflammatory effects make them an attractive option for the reduction of CVD burden in PLWH. Statins, as competitive HMG Co Enzyme A inhibitors, reduce not only cholesterol synthesis through the mevalonate pathway but also isoprenoid formation resulting in increased nitric oxide availability and reduction in post-translational modification of proteins involved in numerous inflammatory pathways (66). These anti-inflammatory and immunomodulatory effects have been demonstrated in many ex vivo models ranging from inhibition of pro-inflammatory Th-17 differentiation to suppression of IL-6 mediated monocyte chemotaxis in aortic epithelial cells (67-69). Simvastatin use reduced circulating pro-inflammatory cytokines IL-6, IL-8 and 
MCP-1 after 6 weeks administration whereas Pitavastain, a synthetic statin, inhibits IL-2, IL6, INFG and TNFa expression in activated T-cells $(70,71)$.

The potential beneficial effects of statins in secondary prevention have also been demonstrated. Lo et. Al., in a study of PLWH showed a reduction in non-calcified plaque volume and high risk features with statin therapy (72). In the SATURN-HIV RCT of rosuvastatin $10 \mathrm{mg}$ versus placebo in PLWH with $\mathrm{LDL}$ concentrations $\leq 3.36 \mathrm{mmol} / \mathrm{L}$ but high inflammatory markers as measured by T-cell activation on flow cytometry and hsCRP, rosuvastatin was associated with a significantly slower progression of atherosclerotic plaque as measured by CIMT (73). Whilst there was no significant difference between the inflammatory endpoint overall, significant reductions in T-cell activation with statin therapy were noted in the subgroup of smokers (74). The REPREIVE trial (Evaluating the Use of pitavastatin to Reduce the Risk of CVD in HIV Adults), a large randomized placebo-controlled trial of pitavastatin on CVD endpoints in PLWH with low estimated CVD risk, is ongoing with initial results (expected in 2020) eagerly awaited. The benefits of statin therapy in preventing CVD events have been demonstrated in other chronic inflammatory conditions such as rheumatoid arthritis, although whether the CVD risk reduction is greater in inflammatory conditions than what is seen in the general population has not yet been demonstrated (75).

\subsection{Smoking Cessation to reduce risk of CVD}

Smoking has consistently been shown to be more prevalent in PLWH with the benefits of smoking cessation in this population demonstrated (76-78). In 2011, using data from the D:A:D study, Petoumenos et al. reported ex-smokers at three years had almost halved their 
risk of CVD events compared to current smokers (79) whereas Helleberg, using data on PLWH participating in the European and North American ART Cohort Collaboration, reported that PLWH who smoke had twice the mortality risk compared to non-smokers (76).

With a move away from boosted ART regimens and consequent potential drug interactions, use of smoking cessation medications such as varicycline and bupoprion, both effective in the general population, can now be considered. However, success rates with current smoking cessation strategies are at best modest, and the use of novel non-pharmacological interventions, such as psychological programs, and use of cell phone-based technologies remain interesting but often infeasible possibilities for most HIV specialist clinics $(80,81)$. However, by regularly reaffirming the benefits of smoking cessation and through the provision of support to individuals who express a desire to stop smoking, HIV specialists may lower CVD risk in this population (82).

\section{Additional Considerations for predicting and managing risk}

Additional factors that, whilst not specific to HIV infection, are more prevalent within the population of PLWH and which may augment CVD risk include recreational drug use, particularly cocaine and amphetamine use $(83,83-87)$. People who inject drugs either currently or historically are over-represented in the population of PLWH but this group may not be adequately represented in research studies or clinical trials. In a large Danish longitudinal study of over 7 years follow-up, injection drug use and use of prescribed methadone was significantly associated with incident CVD (88) with Reece and Hulse reporting that long term opiate use was associated with increased arterial stiffness as measured by pulse wave velocity (89). Although current or historic drug use may not factor 
significantly in general population studies, these data are important to incorporate in studies examining CVD risk in PLWH. By failing to incorporate these potential contributors to CVD risk in PLWH, we risk failing to adequately address the drivers behind excess CVD risk in the population of PLWH, which may also limit development of appropriate strategies to reduce this risk.

Another issue that is consistently associated with cardiovascular risk in epidemiological research, but is rarely factored into clinical studies, is socioeconomic status. In a large multicohort study/meta-analysis comprising over 1.7 million participants with a mean follow-up of 13.3 years, 'low' socioeconomic status was independently associated with cardiovascular mortality, even when adjusted for traditional risk factors (HR $1.29[95 \% \mathrm{Cl}$ 1.16-1.43]) (90). Clinicians thus need to be aware of the potential impact of socioeconomic status on an individual's cardiovascular risk over and above that of the traditional risk factors.

Another population group that requires special consideration is transgender men and women. The role of sex hormones on cardiovascular health is complex and conflicting, differently-designed studies have contributed to uncertainty surrounding their role in development of CVD in PLWH. However, it is known that oestrogen and progesterone hormonal therapy is associated with cardiovascular events especially if used in combination, therefore clinicians must be mindful of concurrent hormonal replacement therapy in transgender individuals when estimating CVD risk (91-93). 
The role of testosterone in CVD is somewhat more controversial. With the known male predominance of CVD, the protective effect of estrogen in premenopausal women and reports of MIs occurring with use of anabolic steroids, testosterone was believed to be deleterious to cardiovascular health. However more recent evidence suggests a potential benefit of testosterone replacement in hypogonadic males in preventing cardiovascular events associated with testosterone deficiency (94-96). Studies examining CVD risk in transgender men, although few in number with a younger age predominance, suggest no additional risk of CVD events in the setting of testosterone replacement therapy, despite deterioration of traditional risk factors such as hypertension and dyslipidemia $(97,98)$. However further studies are necessary in this population to fully elucidate the risk, if any, attributable to hormone replacement therapy.

\section{Conclusion}

Current data point to an increased risk of CVD in PLWH, however the drivers behind this remain multiple and current prediction models tend to underestimate actual risk of CVD in PLWH. However given the prevalence of traditional risk factors in this population, appropriate primary preventative measures such as lipid-lowering treatment and smoking cessation may contribute to a substantial reduction in the burden of CVD in this population. Continued vigilance of ART-induced metabolic derangements is necessary, with avoidance of medications with known associations in individuals with high risk of CVD. Finally, further

well-designed studies are necessary, incorporating the many potential CVD risks, to conclusively identify the major contributors to CVD risk in the population of PLWH. 


\section{Expert opinion}

CVD pathogenesis in HIV infection is multifactorial with the relative contribution of traditional risk factors such as smoking and dyslipidaemia, highly prevalent in treated PLWH, versus HIV specific factors, not yet known. In addition to traditional CVD risk factors, other factors such as chronic HIV viremia, ART, CMV co-infection, chronic inflammation, innate immune activation, the microbiome and microbial translocation may be implicated in the pathogenesis of CVD in PLWH making prediction of CVD risk difficult. Current risk prediction models have been shown to be inadequate at identifying PLWH at risk of CVD but it is unlikely that the large cohort data that would be required to examine these pathways in PLWH with sufficient power would be feasible.

Chronic inflammation undoubtedly plays a role, and the benefit of persistent viral suppression with appropriate ART is well documented. With the roll out of suppressive ART regardless of CD4+ T-cell count, and avoidance of ART previously associated with CVD events, we have seen an encouraging reduction in CVD mortality. However, we know that low grade systemic inflammation together with other immune dysfunction such as innate immune activation can persist in PLWH despite ART and whether these persistent inflammatory changes contribute significantly to CVD pathogenesis in PLWH is less certain. This information is rarely incorporated into risk factor algorithms due to the limited availability of biochemical data within existing cohorts. Further well designed studies examining the role of these inflammatory pathways and other HIV specific factors are needed to fully elucidate the mechanisms behind the increased CVD risk in PLWH. Once 
pathways are identified, we can then attempt to assess their CVD predicative utility in cohort studies.

Targeting inflammatory pathways for CVD prevention in PLWH is an intriguing area for future research. Although results to date have been disappointing (99), the Canakinumab Antiinflammatory Thrombosis Outcome Study (CANTOS), demonstrating a reduction in recurrent AMI, stroke or CVD death with IL-1 beta inhibition in patients with established CVD and evidence of chronic inflammation, finally established inflammation, at least in recurrent disease, as a driver of CVD events in the general population (100).

Statin therapy used successfully in primary prevention strategies, exert anti-inflammatory effects which likely contributes to CVD reduction in those with chronic inflammation (101) and may also prove an effective addition to standard HIV management to reduce CVD morbidity. The REPREIVE trial examining the effect of Pitastatin, a synthetic HMG Coenzyme A inhibitor, on CVD risk in PLWH at low to moderate risk is the largest RCT of its kind comprising of over 7500 participants with HIV. This important study will help answer many of the questions surrounding the effects of statins on inflammation in PLWH and its impact on CVD events. Further studies are ongoing and will likely influence the future direction of primary preventative strategies in PLWH.

In the meantime, clinicians can still make positive impact in reducing CVD risk in PLWH (figure 1). In order to identify PLWH at high risk of developing CVD we would recommend the following: 
- Use a CVD risk algorithm, ideally one validated in a population of PLWH such as the D:A:D 5 and 10 year risk scores, to initially assess CVD risk, bearing in mind the potential inadequacies of these algorithms for accurately predicting CVD risk as discussed above.

- To consider initiating risk reduction strategies earlier in those with additional biomarkers that have been associated with comorbidity and CVD risk such as a persistently lowered CD4+:CD8+ ratio and raised hsCRP (>3mg/L) on consecutive measurements in the absence of other inflammatory causes.

- To consider additional factors in assessment of CVD risk in PLWH such as hormonal therapy and long term recreational drug use associated with CVD events, for example opiates, cocaine and amphetamine use.

In those deemed at high risk of CVD we suggest following international guidelines in managing CVD risk in PLWH (102). We recommend:

- To avoid initiation of NRTI, abacavir and PI based ART in high risk individuals, with the exception of atazanavir, which current evidence suggests is not associated with CVD events. If an at risk individual is already receiving these agents, consider a switch away to alternative therapy

- Consider trial of statin therapy in individuals with multiple CVD risk factors. We would recommend using similar lipid reduction targets as recommended in the general population given the absence of HIV specific data $(103,104)$.

- Consider other primary preventative strategies such as aspirin use as recommended by international guidelines (105) and in accordance with those used in the general 
population. Currently no consistent data suggests an additional benefit of earlier intervention with anti-platelet agents in PLWH.

For all PLWH, consider every consultation an opportunity to re-enforce and emphasise the benefit of appropriate lifestyle modification such as smoking cessation, dietary changes, and increased exercise to reduce CVD risk in this population. In particular, the benefits of smoking cessation have been demonstrated repeatedly, for both CVD and all-cause mortality. Implementation of effective smoking cessation strategies in HIV clinics would be a positive step towards reducing the burden of CVD events and although requiring additional resourcing, the cost-effectiveness of such measures are likely to be worthwhile in the long term.

Similarly, consideration of the metabolic effects of ART on both lipid parameters and CVD risk should be made prior to initiation or switching ART. The recent observation of significant weight gain with the use of TAF and some INSTI is noteworthy and deserves further examination, especially given their recent recommendations for use as first line therapy. Further work should examine the potential molecular and biochemical mechanisms causing weight abnormalities in addition to the metabolic and clinical consequences of these. These findings also highlight the importance of ongoing vigilance for adverse events with HIV treatment.

The benefit of routine targeted screening for CVD in PLWH, other than what is recommended in the general population, with cardiac specific or radiological investigations such as treadmill monitoring and routine CTCA is questionable and to date has not been 
routinely recommended. This may change as further data emerge, however, initial routine assessments with CVD risk estimation as discussed above and electrocardiography are appropriate and are recommended by international guidelines (102).

Whilst waiting for the findings from ongoing research to broaden our understanding of CVD pathogenesis in HIV infection and potential novel risk reduction strategies, a positive impact on the burden of CVD can be made by aggressively managing traditional CVD risk factors and with the careful consideration of ART in PLWH. Simple consideration of the factors contributing to CVD risk can help guide clinicians to direct resources at those who are likely to benefit most from interventions to reduce CVD incidence and to continue to promote and foster healthy ageing in PLWH.

\section{Funding}

This paper was not funded.

\section{Declaration of interest}

The authors have no relevant affiliations or financial involvement with any organization or entity with a financial interest in or financial conflict with the subject matter or materials discussed in the manuscript. This includes employment, consultancies, honoraria, stock ownership or options, expert testimony, grants or patents received or pending, or royalties.

\section{Reviewer disclosures}

Peer reviewers on this manuscript have no relevant financial or other relationships to disclose. 


\section{References}

1. Durand M, Sheehy O, Baril J-G, Lelorier J, Tremblay CL. Association Between HIV Infection, Antiretroviral Therapy, and Risk of Acute Myocardial Infarction: A Cohort and Nested Case-Control Study Using Québec's Public Health Insurance Database. JAIDS J Acquir Immune Defic Syndr. 2011 Jul 1;57(3):245.

2. Currier JS, Taylor A, Boyd F, Dezii CM, Kawabata H, Burtcel B, et al. Coronary heart disease in HIV-infected individuals. J Acquir Immune Defic Syndr 1999. 2003 Aug 1;33(4):506-12.

3. Paisible A-L, Chang C-CH, So-Armah KA, Butt AA, Leaf DA, Budoff M, et al. HIV infection, cardiovascular disease risk factor profile, and risk for acute myocardial infarction. J Acquir Immune Defic Syndr 1999. 2015 Feb 1;68(2):209-16.

4. Silverberg MJ, Leyden WA, Xu L, Horberg MA, Chao CR, Towner WJ, et al. Immunodeficiency and risk of myocardial infarction among HIV-positive individuals with access to care. J Acquir Immune Defic Syndr 1999. 2014 Feb 1;65(2):160-6.

5. Shah ASV, Stelzle D, Lee KK, Beck EJ, Alam S, Clifford S, et al. Global Burden of Atherosclerotic Cardiovascular Disease in People Living With HIV. Circulation. 2018 $11 ; 138(11): 1100-12$.

6. Freiberg MS, Chang C-CH, Kuller LH, Skanderson M, Lowy E, Kraemer KL, et al. HIV Infection and the Risk of Acute Myocardial Infarction. JAMA Intern Med. 2013 Apr 22;173(8):614-22.

7. Lo J, Abbara S, Shturman L, Soni A, Wei J, Rocha-Filho JA, et al. Increased prevalence of subclinical coronary atherosclerosis detected by coronary computed tomography angiography in HIV-infected men. AIDS Lond Engl. 2010 Jan 16;24(2):243-53.

8. Post WS, Budoff M, Kingsley L, Palella FJ, Witt MD, Li X, et al. Associations between HIV infection and subclinical coronary atherosclerosis. Ann Intern Med. 2014 Apr $1 ; 160(7): 458-67$.

9. Lai H, Moore R, Celentano DD, Gerstenblith G, Treisman G, Keruly JC, et al. HIV Infection Itself May Not Be Associated With Subclinical Coronary Artery Disease Among African Americans Without Cardiovascular Symptoms. J Am Heart Assoc. 2016 Mar 24;5(3):e002529.

10. Tarr PE, Ledergerber B, Calmy A, Doco-Lecompte T, Marzel A, Weber R, et al. Subclinical coronary artery disease in Swiss HIV-positive and HIV-negative persons. Eur Heart J. 2018 14;39(23):2147-54.

11. Friis-Møller N, Sabin CA, Weber R, d'Arminio Monforte A, El-Sadr WM, Reiss P, et al. Combination antiretroviral therapy and the risk of myocardial infarction. N Engl J Med. 2003 Nov 20;349(21):1993-2003. 
12. DAD Study Group, Friis-Møller N, Reiss P, Sabin CA, Weber R, Monforte A d'Arminio, et al. Class of antiretroviral drugs and the risk of myocardial infarction. N Engl J Med. 2007 Apr 26;356(17):1723-35.

13. Ryom L, Lundgren JD, El-Sadr W, Reiss P, Kirk O, Law M, et al. Cardiovascular disease and use of contemporary protease inhibitors: the D:A:D international prospective multicohort study. Lancet HIV. 2018;5(6):e291-300.

14. D:A:D Study Group, Sabin CA, Worm SW, Weber R, Reiss P, El-Sadr W, et al. Use of nucleoside reverse transcriptase inhibitors and risk of myocardial infarction in HIVinfected patients enrolled in the D:A:D study: a multi-cohort collaboration. Lancet Lond Engl. 2008 Apr 26;371(9622):1417-26.

15. O’Halloran JA, Dunne E, Tinago W, Denieffe S, Kenny D, Mallon PWG. Switching from abacavir to tenofovir disoproxil fumarate is associated with rises in soluble glycoprotein VI, suggesting changes in platelet-collagen interactions. AIDS Lond Engl. 2018 24;32(7):861-6.

16. Satchell CS, O'Halloran JA, Cotter AG, Peace AJ, O'Connor EF, Tedesco AF, et al. Increased platelet reactivity in HIV-1-infected patients receiving abacavir-containing antiretroviral therapy. J Infect Dis. 2011 Oct 15;204(8):1202-10.

17. Ding X, Andraca-Carrera E, Cooper C, Miele P, Kornegay C, Soukup M, et al. No association of abacavir use with myocardial infarction: findings of an FDA metaanalysis. J Acquir Immune Defic Syndr 1999. 2012 Dec 1;61(4):441-7.

18. Islam FM, Wu J, Jansson J, Wilson DP. Relative risk of cardiovascular disease among people living with HIV: a systematic review and meta-analysis. HIV Med. 2012 Sep;13(8):453-68.

19. Nguyen A, Calmy A, Delhumeau C, Mercier I, Cavassini M, Mello AF, et al. A randomized cross-over study to compare raltegravir and efavirenz (SWITCH-ER study). AIDS Lond Engl. 2011 Jul 31;25(12):1481-7.

20. Lennox JL, DeJesus E, Lazzarin A, Pollard RB, Madruga JVR, Berger DS, et al. Safety and efficacy of raltegravir-based versus efavirenz-based combination therapy in treatment-naive patients with HIV-1 infection: a multicentre, double-blind randomised controlled trial. Lancet Lond Engl. 2009 Sep 5;374(9692):796-806.

21. Mallon PGW, Brunet L, Fusco JS, Prajapati G, Beyer A, Fusco G, et al. Changes in lipids after a direct switch from TDF to TAF. Conf Retroviruses Oppertunistic Infect [Internet]. 2019 Mar [cited 2020 Jan 20]; Available from:

http://www.croiconference.org/sessions/changes-lipids-after-direct-switch-tdf-taf

22. Sax PE, Erlandson KM, Lake JE, McComsey GA, Orkin C, Esser S, et al. Weight Gain Following Initiation of Antiretroviral Therapy: Risk Factors in Randomized Comparative Clinical Trials. Clin Infect Dis Off Publ Infect Dis Soc Am. 2019 Oct 14;

23. Venter WDF, Moorhouse M, Sokhela S, Fairlie L, Mashabane N, Masenya M, et al. Dolutegravir plus Two Different Prodrugs of Tenofovir to Treat HIV. N Engl J Med. 2019 29;381(9):803-15. 
24. CD4+ Count-Guided Interruption of Antiretroviral Treatment. N Engl J Med. 2006;14.

25. The INSIGHT START Study Group. Initiation of Antiretroviral Therapy in Early Asymptomatic HIV Infection. N Engl J Med. 2015 Aug 27;373(9):795-807.

26. Crowell TA, Gebo KA, Blankson JN, Korthuis PT, Yehia BR, Rutstein RM, et al. Hospitalization Rates and Reasons Among HIV Elite Controllers and Persons With Medically Controlled HIV Infection. J Infect Dis. 2015 Jun 1;211(11):1692-702.

27. Imami N, Westrop SJ, Grageda N, Herasimtschuk AA. Long-Term Non-Progression and Broad HIV-1-Specific Proliferative T-Cell Responses. Front Immunol. 2013;4:58.

28. Hsue PY, Hunt PW, Schnell A, Kalapus SC, Hoh R, Ganz P, et al. Role of Viral Replication, Antiretroviral Therapy, and Immunodeficiency in HIV - Associated Atherosclerosis. AIDS Lond Engl. 2009 Jun 1;23(9):1059-67.

29. Hunt PW, Brenchley J, Sinclair E, McCune JM, Roland M, Page-Shafer K, et al. Relationship between $\mathrm{T}$ cell activation and CD4+ T cell count in HIV-seropositive individuals with undetectable plasma HIV RNA levels in the absence of therapy. J Infect Dis. 2008 Jan 1;197(1):126-33.

30. Pereyra F, Lo J, Triant VA, Wei J, Buzon MJ, Fitch KV, et al. Increased Coronary Atherosclerosis and Immune Activation in HIV-1 Elite Controllers. AIDS Lond Engl. 2012 Nov 28;26(18):2409-12.

31. Brusca R, Hanna D, Wada N, Blankson J, Witt M, Jacobson L, et al. Subclinical cardiovascular disease in HIV controller and long-term nonprogressor populations. HIV Med. 2020 Apr;21(4):217-27.

32. Noël N, Gominet M, Meyer L, Boufassa F, Lambotte O. Cardiovascular Events in the French ANRS HIV Controller Cohort. J Acquir Immune Defic Syndr 1999. 2019 Oct $1 ; 82(2): \mathrm{e} 32-4$.

33. Noël N, Saez-Cirion A, Avettand-Fenoël V, Boufassa F, Lambotte O. HIV controllers: to treat or not to treat? Is that the right question? Lancet HIV. 2019 Dec;6(12):e878-84.

34. Smith CJ, Ryom L, Weber R, Morlat P, Pradier C, Reiss P, et al. Trends in underlying causes of death in people with HIV from 1999 to 2011 (D:A:D): a multicohort collaboration. Lancet Lond Engl. 2014 Jul 19;384(9939):241-8.

35. Klein DB, Leyden WA, Xu L, Chao CR, Horberg MA, Towner WJ, et al. Declining Relative Risk for Myocardial Infarction Among HIV-Positive Compared With HIVNegative Individuals With Access to Care. Clin Infect Dis. 2015 Apr 15;60(8):1278-80.

36. Hanna DB, Ramaswamy C, Kaplan RC, Kizer JR, Anastos K, Daskalakis D, et al. Trends in Cardiovascular Disease Mortality Among Persons With HIV in New York City, 20012012. Clin Infect Dis Off Publ Infect Dis Soc Am. 2016 15;63(8):1122-9.

37. Klein DB, Leyden WA, Xu L, Chao CR, Horberg MA, Towner WJ, et al. Declining relative risk for myocardial infarction among HIV-positive compared with HIV-negative individuals with access to care. Clin Infect Dis Off Publ Infect Dis Soc Am. 2015 Apr $15 ; 60(8): 1278-80$. 
38. Thompson-Paul AM, Lichtenstein KA, Armon C, Palella FJ, Skarbinski J, Chmiel JS, et al. Cardiovascular Disease Risk Prediction in the HIV Outpatient Study. Clin Infect Dis Off Publ Infect Dis Soc Am. 2016 Dec 1;63(11):1508-16.

39. Law MG, Friis-Møller N, El-Sadr WM, Weber R, Reiss P, D’Arminio Monforte A, et al. The use of the Framingham equation to predict myocardial infarctions in HIV-infected patients: comparison with observed events in the D:A:D Study. HIV Med. 2006 May;7(4):218-30.

40. Triant VA, Perez J, Regan S, Massaro JM, Meigs JB, Grinspoon SK, et al. Cardiovascular Risk Prediction Functions Underestimate Risk in HIV Infection. Circulation. 2018 22;137(21):2203-14.

41. van Zoest RA, Law M, Sabin CA, Vaartjes I, van der Valk M, Arends JE, et al. Predictive Performance of Cardiovascular Disease Risk Prediction Algorithms in People Living With HIV. J Acquir Immune Defic Syndr 1999. 2019 Aug 15;81(5):562-71.

42. Friis-Møller N, Thiébaut R, Reiss P, Weber R, Monforte AD, De Wit S, et al. Predicting the risk of cardiovascular disease in HIV-infected patients: the data collection on adverse effects of anti-HIV drugs study. Eur J Cardiovasc Prev Rehabil Off J Eur Soc Cardiol Work Groups Epidemiol Prev Card Rehabil Exerc Physiol. 2010 Oct;17(5):491-501.

43. Parra S, Coll B, Aragonés G, Marsillach J, Beltrán R, Rull A, et al. Nonconcordance between subclinical atherosclerosis and the calculated Framingham risk score in HIVinfected patients: relationships with serum markers of oxidation and inflammation. HIV Med. 2010 Apr;11(4):225-31.

44. Serrano-Villar S, Estrada V, Gómez-Garre D, Ávila M, Fuentes-Ferrer M, San RJ, et al. Diagnosis of subclinical atherosclerosis in HIV-infected patients: higher accuracy of the D:A:D risk equation over Framingham and SCORE algorithms. Eur J Prev Cardiol. 2014 Jun;21(6):739-48.

45. Dhillon S, Sabin CA, Alagaratnam J, Bagkeris E, Post FA, Boffito M, et al. Level of agreement between frequently used cardiovascular risk calculators in people living with HIV. HIV Med. 2019 May;20(5):347-52.

46. Mosepele M, Hemphill LC, Palai T, Nkele I, Bennett K, Lockman S, et al. Cardiovascular disease risk prediction by the American College of Cardiology (ACC)/American Heart Association (AHA) Atherosclerotic Cardiovascular Disease (ASCVD) risk score among HIV-infected patients in sub-Saharan Africa. PLoS ONE [Internet]. 2017 Feb 24 [cited 2019 Oct 4];12(2). Available from: https://www.ncbi.nlm.nih.gov/pmc/articles/PMC5325544/

47. Pirš M, Jug B, Eržen B, Šabović M, Karner P, Poljak M, et al. Cardiovascular risk assessment in HIV-infected male patients: a comparison of Framingham, SCORE, PROCAM and DAD risk equations. Acta Dermatovenerol Alp Pannonica Adriat. 2014;23(3):43-7.

48. Markowicz S, Delforge M, Necsoi C, De Wit S. Cardiovascular risk evaluation of HIVpositive patients in a case-control study: comparison of the D:A:D and Framingham 
equations. J Int AIDS Soc [Internet]. 2014 Nov 2 [cited 2019 Oct 4];17(4Suppl 3). Available from: https://www.ncbi.nlm.nih.gov/pmc/articles/PMC4224912/

49. Nery MW, Martelli CMT, Silveira EA, de Sousa CA, Falco M de O, de Castro A de CO, et al. Cardiovascular risk assessment: a comparison of the Framingham, PROCAM, and DAD equations in HIV-infected persons. ScientificWorldJournal. 2013;2013:969281.

50. Noumegni SR, Ama VJM, Assah FK, Bigna JJ, Nansseu JR, Kameni JAM, et al. Assessment of the agreement between the Framingham and DAD risk equations for estimating cardiovascular risk in adult Africans living with HIV infection: a crosssectional study. Trop Dis Travel Med Vaccines. 2017;3:12.

51. Kim SB, Kim YC, Kim MH, Song JE, Oh DH, Ahn JY, et al. A comparison of the predicted risk for cardiovascular disease between HIV-infected and uninfected persons in Korea. Scand J Infect Dis. 2013 Nov;45(11):855-62.

52. De Socio GV, Pucci G, Baldelli F, Schillaci G. Observed versus predicted cardiovascular events and all-cause death in HIV infection: a longitudinal cohort study. BMC Infect Dis. 2017 12;17(1):414.

53. Petoumenos K, Reiss P, Ryom L, Rickenbach M, Sabin CA, El-Sadr W, et al. Increased risk of cardiovascular disease (CVD) with age in HIV-positive men: a comparison of the D:A:D CVD risk equation and general population CVD risk equations. HIV Med. 2014 Nov;15(10):595-603.

54. Clumeck N, Pozniak A, Raffi F, EACS Executive Committee. European AIDS Clinical Society (EACS) guidelines for the clinical management and treatment of HIV-infected adults. HIV Med. 2008 Feb;9(2):65-71.

55. Castilho JL, Shepherd BE, Koethe J, Turner M, Bebawy S, Logan J, et al. CD4+/CD8+ ratio, age, and risk of serious noncommunicable diseases in HIV-infected adults on antiretroviral therapy. AIDS Lond Engl. 2016 Mar 27;30(6):899-908.

56. Menozzi M, Zona S, Santoro A, Carli F, Stentarelli C, Mussini C, et al. CD4/CD8 ratio is not predictive of multi-morbidity prevalence in HIV-infected patients but identify patients with higher CVD risk. J Int AIDS Soc [Internet]. 2014 Nov 2 [cited 2019 Nov 23];17(4Suppl 3). Available from:

https://www.ncbi.nlm.nih.gov/pmc/articles/PMC4225275/

57. Bernal Morell E, Serrano Cabeza J, Muñoz Á, Marín I, Masiá M, Gutiérrez F, et al. The CD4/CD8 Ratio is Inversely Associated with Carotid Intima-Media Thickness Progression in Human Immunodeficiency Virus-Infected Patients on Antiretroviral Treatment. AIDS Res Hum Retroviruses. 2016;32(7):648-53.

58. Serrano-Villar S, Moreno S, Fuentes-Ferrer M, Sánchez-Marcos C, Avila M, Sainz T, et al. The CD4:CD8 ratio is associated with markers of age-associated disease in virally suppressed HIV-infected patients with immunological recovery. HIV Med. 2014 Jan;15(1):40-9.

59. Hsu DC, Ma YF, Hur S, Li D, Rupert A, Scherzer R, et al. Plasma IL-6 levels are independently associated with atherosclerosis and mortality in HIV-infected individuals on suppressive antiretroviral therapy. AIDS Lond Engl. 2016 Aug 24;30(13):2065-74. 
60. Hoel H, Ueland T, Knudsen A, Kjær A, Michelsen AE, Sagen EL, et al. Soluble Markers of Interleukin 1 Activation as Predictors of First-Time Myocardial Infarction in HIVInfected Individuals. J Infect Dis [Internet]. [cited 2019 Dec 21]; Available from: https://academic.oup.com/jid/advance-article/doi/10.1093/infdis/jiz253/5488093

61. Monroe AK, Chander G, Moore RD. Control of medical comorbidities in individuals with HIV. J Acquir Immune Defic Syndr 1999. 2011 Dec 15;58(5):458-62.

62. Okeke NL, Chin T, Clement M, Chow S-C, Hicks CB. Coronary artery disease risk reduction in HIV-infected persons: a comparative analysis. AIDS Care. 2016;28(4):47582.

63. Emmanuel S, Nadel J, Fagan D, Teeraananchai S, Law M, Holloway CJ. Patients with HIV and coronary disease: are we meeting national guidelines? Sex Health. 2018;15(1):83-5.

64. Clement ME, Park LP, Navar AM, Okeke NL, Pencina MJ, Douglas PS, et al. Statin Utilization and Recommendations Among HIV- and HCV-infected Veterans: A Cohort Study. Clin Infect Dis Off Publ Infect Dis Soc Am. 2016 01;63(3):407-13.

65. De Socio GV, Ricci E, Parruti G, Calza L, Maggi P, Celesia BM, et al. Statins and Aspirin use in HIV-infected people: gap between European AIDS Clinical Society guidelines and clinical practice: the results from HIV-HY study. Infection. 2016 Oct;44(5):589-97.

66. Wang C-Y, Liu P-Y, Liao JK. Pleiotropic effects of statin therapy. Trends Mol Med. 2008 Jan; 14(1):37-44.

67. Kagami S, Owada T, Kanari H, Saito Y, Suto A, Ikeda K, et al. Protein geranylgeranylation regulates the balance between Th17 cells and Foxp3+ regulatory $\mathrm{T}$ cells. Int Immunol. 2009 Jun 1;21(6):679-89.

68. Jougasaki M, Ichiki T, Takenoshita Y, Setoguchi M. Statins suppress interleukin-6induced monocyte chemo-attractant protein-1 by inhibiting Janus kinase/signal transducers and activators of transcription pathways in human vascular endothelial cells. Br J Pharmacol. 2010 Mar;159(6):1294-303.

69. Bu D, Tarrio M, Grabie N, Zhang Y, Yamazaki H, Stavrakis G, et al. Statin-induced Krüppel-like factor 2 expression in human and mouse $\mathrm{T}$ cells reduces inflammatory and pathogenic responses. J Clin Invest. 2010 Jun;120(6):1961-70.

70. Rezaie-Majd A, Maca T, Bucek RA, Valent P, Müller MR, Husslein P, et al. Simvastatin reduces expression of cytokines interleukin-6, interleukin-8, and monocyte chemoattractant protein-1 in circulating monocytes from hypercholesterolemic patients. Arterioscler Thromb Vasc Biol. 2002 Jul 1;22(7):1194-9.

71. Chen LW, Lin C-S, Tsai M-C, Shih S-F, Lim ZW, Chen S-J, et al. Pitavastatin Exerts Potent Anti-Inflammatory and Immunomodulatory Effects via the Suppression of AP-1 Signal Transduction in Human T Cells. Int J Mol Sci. 2019 Jul 19;20(14).

72. Lo J, Lu MT, Ihenachor EJ, Wei J, Looby SE, Fitch KV, et al. Effects of statin therapy on coronary artery plaque volume and high-risk plaque morphology in HIV-infected patients 
with subclinical atherosclerosis: a randomised, double-blind, placebo-controlled trial. Lancet HIV. 2015 Feb;2(2):e52-63.

73. Longenecker CT, Sattar A, Gilkeson R, Mccomsey GA. Rosuvastatin Slows Progression of Subclinical Atherosclerosis in Patients with Treated HIV Infection. AIDS Lond Engl. 2016 Sep 10;30(14):2195-203.

74. Hileman CO, McComsey GA. Short Communication: The Effect of Rosuvastatin on Vascular Disease Differs by Smoking Status in Treated HIV Infection. AIDS Res Hum Retroviruses. 2018 Mar 1;34(3):282-5.

75. Kitas GD, Nightingale P, Armitage J, Sattar N, Belch JJF, Symmons DPM. A Multicenter, Randomized, Placebo-Controlled Trial of Atorvastatin for the Primary Prevention of Cardiovascular Events in Patients With Rheumatoid Arthritis. Arthritis Rheumatol Hoboken Nj. 2019 Sep;71(9):1437-49.

76. Helleberg M, May MT, Ingle SM, Dabis F, Reiss P, Fätkenheuer G, et al. Smoking and life expectancy among HIV-infected individuals on antiretroviral therapy in Europe and North America. AIDS Lond Engl. 2015 Jan 14;29(2):221 -9.

77. Marcus JL, Chao CR, Leyden WA, Xu L, Quesenberry CP, Klein DB, et al. Narrowing the Gap in Life Expectancy Between HIV-Infected and HIV-Uninfected Individuals With Access to Care. J Acquir Immune Defic Syndr 1999. 2016 01;73(1):39-46.

78. Reddy KP, Parker RA, Losina E, Baggett TP, Paltiel AD, Rigotti NA, et al. Impact of Cigarette Smoking and Smoking Cessation on Life Expectancy Among People With HIV: A US-Based Modeling Study. J Infect Dis. 2016 Dec 1;214(11):1672-81.

79. Petoumenos K, Worm S, Reiss P, de Wit S, d'Arminio Monforte A, Sabin C, et al. Rates of cardiovascular disease following smoking cessation in patients with HIV infection: results from the D:A:D study(*). HIV Med. 2011 Aug;12(7):412-21.

80. Whittaker R, McRobbie H, Bullen C, Rodgers A, Gu Y. Mobile phone-based interventions for smoking cessation. Cochrane Database Syst Rev. 2016 Apr 10;4:CD006611.

81. O’Cleirigh C, Zvolensky MJ, Smits JAJ, Labbe AK, Coleman JN, Wilner JG, et al. Integrated Treatment for Smoking Cessation, Anxiety, and Depressed Mood in People Living With HIV: A Randomized Controlled Trial. J Acquir Immune Defic Syndr 1999. 2018 01;79(2):261-8.

82. Pacek LR, Rass O, Johnson MW. Positive smoking cessation-related interactions with HIV care providers increase the likelihood of interest in cessation among HIV-positive cigarette smokers. AIDS Care. 2017;29(10):1309-14.

83. Westover AN, Nakonezny PA, Haley RW. Acute myocardial infarction in young adults who abuse amphetamines. Drug Alcohol Depend. 2008 Jul 1;96(1-2):49-56.

84. Qureshi AI, Suri MF, Guterman LR, Hopkins LN. Cocaine use and the likelihood of nonfatal myocardial infarction and stroke: data from the Third National Health and Nutrition Examination Survey. Circulation. 2001 Jan 30;103(4):502-6. 
85. Jones JH, Weir WB. Cocaine-induced chest pain. Clin Lab Med. 2006 Mar;26(1):127-46, viii.

86. Minor RL, Scott BD, Brown DD, Winniford MD. Cocaine-induced myocardial infarction in patients with normal coronary arteries. Ann Intern Med. 1991 Nov 15;115(10):797806.

87. Mittleman MA, Mintzer D, Maclure M, Tofler GH, Sherwood JB, Muller JE. Triggering of myocardial infarction by cocaine. Circulation. 1999 Jun 1;99(21):2737-41.

88. Thylstrup B, Clausen T, Hesse M. Cardiovascular disease among people with drug use disorders. Int J Public Health. 2015 Sep;60(6):659-68.

89. Reece AS, Hulse GK. Lifetime opiate exposure as an independent and interactive cardiovascular risk factor in males: a cross-sectional clinical study. Vasc Health Risk Manag. 2013;9:551-61.

90. Stringhini S, Carmeli C, Jokela M, Avendaño M, Muennig P, Guida F, et al.

Socioeconomic status and the $25 \times 25$ risk factors as determinants of premature mortality: a multicohort study and meta-analysis of 1.7 million men and women. Lancet Lond Engl. 2017 25;389(10075):1229-37.

91. Kemmeren JM, Tanis BC, van den Bosch MAAJ, Bollen ELEM, Helmerhorst FM, van der Graaf Y, et al. Risk of Arterial Thrombosis in Relation to Oral Contraceptives (RATIO) study: oral contraceptives and the risk of ischemic stroke. Stroke. 2002 May;33(5):1202-8.

92. Sare GM, Gray LJ, Bath PMW. Association between hormone replacement therapy and subsequent arterial and venous vascular events: a meta-analysis. Eur Heart J. 2008 Aug;29(16):2031-41.

93. Asscheman H, Giltay EJ, Megens JAJ, de Ronde WP, van Trotsenburg MAA, Gooren LJG. A long-term follow-up study of mortality in transsexuals receiving treatment with cross-sex hormones. Eur J Endocrinol. 2011 Apr;164(4):635-42.

94. Traish AM, Haider A, Haider KS, Doros G, Saad F. Long-Term Testosterone Therapy Improves Cardiometabolic Function and Reduces Risk of Cardiovascular Disease in Men with Hypogonadism: A Real-Life Observational Registry Study Setting Comparing Treated and Untreated (Control) Groups. J Cardiovasc Pharmacol Ther. 2017 Sep;22(5):414-33.

95. Corona G, Rastrelli G, Monami M, Guay A, Buvat J, Sforza A, et al. Hypogonadism as a risk factor for cardiovascular mortality in men: a meta-analytic study. Eur J Endocrinol. 2011 Nov;165(5):687-701.

96. Rastrelli G, Dicuio M, Reismann Y, Sforza A, Maggi M, Corona G. Cardiovascular impact of testosterone therapy for hypogonadism. Expert Rev Cardiovasc Ther. 2018 Sep;16(9):617-25.

97. Streed CG, Harfouch O, Marvel F, Blumenthal RS, Martin SS, Mukherjee M. Cardiovascular Disease Among Transgender Adults Receiving Hormone Therapy: A Narrative Review. Ann Intern Med. 2017 Aug 15;167(4):256. 
98. Maraka S, Singh Ospina N, Rodriguez-Gutierrez R, Davidge-Pitts CJ, Nippoldt TB, Prokop LJ, et al. Sex Steroids and Cardiovascular Outcomes in Transgender Individuals: A Systematic Review and Meta-Analysis. J Clin Endocrinol Metab. 2017 01;102(11):3914-23.

99. Hsue PY, Ribaudo HJ, Deeks SG, Bell T, Ridker PM, Fichtenbaum C, et al. Safety and Impact of Low-dose Methotrexate on Endothelial Function and Inflammation in Individuals With Treated Human Immunodeficiency Virus: AIDS Clinical Trials Group Study A5314. Clin Infect Dis Off Publ Infect Dis Soc Am. 2019 Jun 1;68(11):1877-86.

100. Ridker PM, Everett BM, Thuren T, MacFadyen JG, Chang WH, Ballantyne C, et al. Antiinflammatory Therapy with Canakinumab for Atherosclerotic Disease. N Engl J Med. 2017 Sep 21;377(12):1119-31.

101. Ridker PM, Danielson E, Fonseca FAH, Genest J, Gotto AM, Kastelein JJP, et al. Rosuvastatin to Prevent Vascular Events in Men and Women with Elevated C-Reactive Protein. N Engl J Med. 2008 Nov 20;359(21):2195-207.

102. Clumeck N, Pozniak A, Raffi F, EACS Executive Committee. European AIDS Clinical Society (EACS) guidelines for the clinical management and treatment of HIVinfected adults. HIV Med. 2008 Feb;9(2):65-71.

103. Grundy SM, Stone NJ, Bailey AL, Beam C, Birtcher KK, Blumenthal RS, et al. 2018 AHA/ACC/AACVPR/AAPA/ABC/ACPM/ADA/AGS/APhA/ASPC/NLA/PCNA Guideline on the Management of Blood Cholesterol. J Am Coll Cardiol. 2019 Jun;73(24):e285-350.

104. Mach F, Baigent C, Catapano AL, Koskinas KC, Casula M, Badimon L, et al. 2019 ESC/EAS Guidelines for the management of dyslipidaemias: lipid modification to reduce cardiovascular riskThe Task Force for the management of dyslipidaemias of the European Society of Cardiology (ESC) and European Atherosclerosis Society (EAS). Eur Heart J. 2020 Jan 1;41(1):111-88.

105. Arnett Donna K., Blumenthal Roger S., Albert Michelle A., Buroker Andrew B., Goldberger Zachary D., Hahn Ellen J., et al. 2019 ACC/AHA Guideline on the Primary Prevention of Cardiovascular Disease: A Report of the American College of Cardiology/American Heart Association Task Force on Clinical Practice Guidelines. Circulation. 2019 Sep 10;140(11):e596-646.

106. Mary-Krause M, Cotte L, Simon A, Partisani M, Costagliola D, Database and the $\mathrm{CEG}$ from the $\mathrm{FH}$. Increased risk of myocardial infarction with duration of protease inhibitor therapy in HIV-infected men. AIDS. 2003 Nov 21;17(17):2479.

107. Drozd DR, Kitahata MM, Althoff KN, Zhang J, Gange SJ, Napravnik S, et al. Increased Risk of Myocardial Infarction in HIV-Infected Individuals in North America Compared With the General Population. J Acquir Immune Defic Syndr 1999. 2017 15;75(5):568-76. 
Figure 1

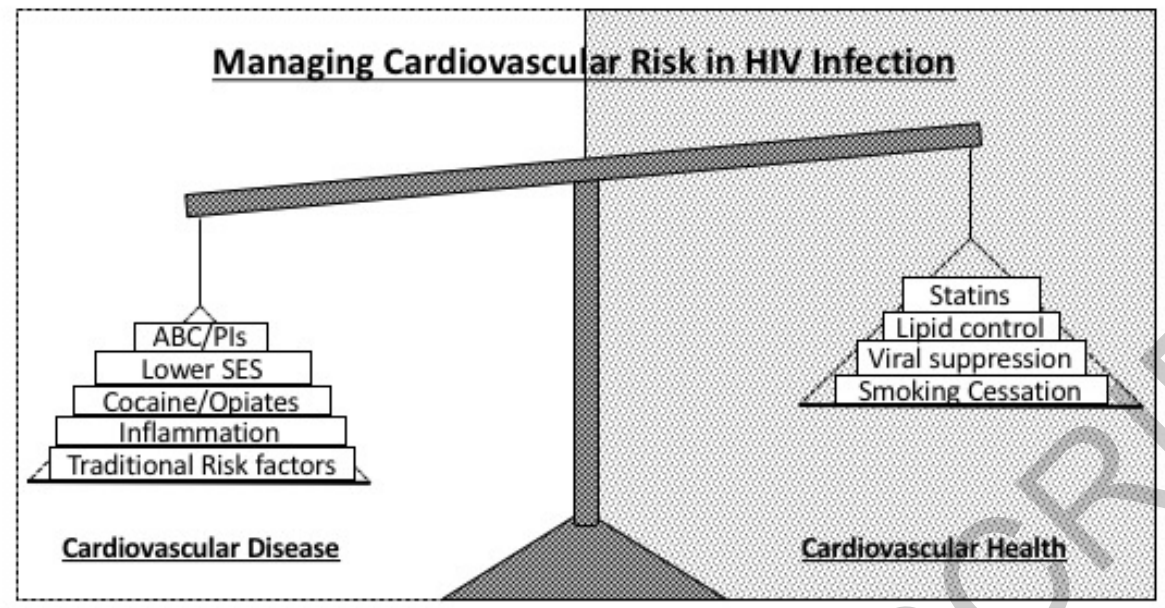

Figure 1: Factors to consider in managing CVD risk in PLWH

$\mathrm{ABC}$; Abacavir, PI; protease inhibitors, SES; socioeconomic status 
Table 1: Studies examining CVD prevalence in PLWH

\begin{tabular}{|c|c|c|c|c|c|c|}
\hline Year & Authors & Study Setting & Demographics & CVD definition & Observed CVD prevalence & Reference \\
\hline 2003 & Currier JS et al. & $\begin{array}{l}\text { California Medicaid Cohort, } \\
\text { USA }\end{array}$ & $\begin{array}{l}28,513 \text { PLWH, } 72 \% \text { male, } 42.8 \% \\
\text { aged } 35-44 \text { years, } 52.7 \% \text { ART } \\
\text { experienced }\end{array}$ & $\begin{array}{l}\mathrm{MI} \text {, angina pectoris, coronary } \\
\text { atherosclerosis, other IHD and } \\
\mathrm{CVD} \text {, unspecified (ICD-9 coding) }\end{array}$ & $\begin{array}{l}\text { Overall incidence per } 100 \text { person-years (PY): PLWH 2.83; HIV } \\
\text { negative } 3.64 \text {. CHD incidence significantly higher in younger } \\
\text { PLWH: } 18-24 \text { years relative risk (RR) }(95 \% \text { confidence interval } \\
\text { (CI)) } 6.76(3.36,13.58), 25-34 \text { years RR } 2.16(1.81,2.58) \text {. }\end{array}$ & 2 \\
\hline 2017 & Drozd DR et al. & $\begin{array}{l}\text { NA-ACCORD Cohort, USA, } \\
\text { Canada }\end{array}$ & $\begin{array}{l}29,169 \text { PLWH, } 36 \% \text { aged } 40-49 \\
\text { years, } 83 \% \text { male, } 54.5 \% \text { ART } \\
\text { exposed }\end{array}$ & $\begin{array}{l}\text { Type } 1 \mathrm{Ml} \text { (retrospectively } \\
\text { health record coding and } \\
\text { adjudicated by study team) }\end{array}$ & Crude Incidence rate $2.57(95 \% \mathrm{Cl} 2.30,2.86)$ per 1,000 PY. & 106 \\
\hline 2011 & Durand $\mathrm{M}$ et al. & $\begin{array}{l}\text { Canadian health registry } \\
\text { data; Cohort and nested } \\
\text { case control study }\end{array}$ & $\begin{array}{l}7053 \text { PLWH, Median age } 37 \\
\text { years, } 78 \% \text { male, } 76.2 \% \text { ART } \\
\text { experienced }\end{array}$ & $\begin{array}{l}\text { Acute } \mathrm{Ml} \text { retrospectively } \\
\text { identified by health record } \\
\text { coding }\end{array}$ & $\begin{array}{l}\text { Incidence rate per 1,000 PY }(95 \% \mathrm{CI}) \text { : PLWH } 3.88(3.26,4.58) ; \text { HIV } \\
\text { negative } 2.21(1.93,2.52) \text {. }\end{array}$ & 1 \\
\hline 2013 & Freiberg MS et al. & $\begin{array}{l}\text { Veterans Ageing Cohort } \\
\text { Study, USA }\end{array}$ & $\begin{array}{l}27,350 \text { PLWH, mean (standard } \\
\text { deviation (SD)) age } 48.2(9.5) \\
\text { years, } 97.3 \% \text { male, } 49.2 \% \text { on } \\
\text { ART }\end{array}$ & $\begin{array}{l}\text { Acute MI (adjudicated VA data, } \\
\text { ICD-9 coding and death } \\
\text { certification) }\end{array}$ & $\begin{array}{l}\text { Incidence rate per } 1,000 \mathrm{PY}(95 \% \mathrm{Cl}): \text { age group } 30-39 \text { years } 2.19 \\
(0.89,5.58): 40-49 \text { years } 1.34(1.04,1.72): 50-59 \text { years } 1.80(1.47 \text {, } \\
1.21): 60-69 \text { years } 1.53(1.03,2.26): 70-79 \text { years } 1.50(0.86,2.57) \text { : } \\
80-89 \text { years } 0.63(0.12,2.25) .\end{array}$ & 6 \\
\hline 2003 & Friis-Møller $\mathrm{N}$ et al. & $\begin{array}{l}\mathrm{D}: \mathrm{A}: \mathrm{D} \\
\text { multinational collaboration }\end{array}$ & $\begin{array}{llr}23,468 & \text { PLWH, } 75.9 \% & \text { male, } \\
\text { median (interquartile } & \text { range) } \\
\text { age } 39 & \text { (34-45) years, } 80.8 \% \\
\text { ART exposed }\end{array}$ & $\begin{array}{l}\text { Prospectively collected } \mathrm{Ml} \text { as } \\
\text { reported to study team and } \\
\text { meeting predefined criteria as } \\
\text { defined in study protocol. . }\end{array}$ & $\begin{array}{l}\text { Incidence rate per 1,000 PY 3.5; RR }(95 \% \mathrm{Cl}) \text { per additional year } \\
\text { of ART exposure: } 1.22(1.09,1.38) .\end{array}$ & 33 \\
\hline 2003 & $\begin{array}{l}\text { Mary-Krause, } \mathrm{M} \text { et } \\
\text { al. }\end{array}$ & $\begin{array}{l}\text { French Hospital Database } \\
\text { on HIV registry, France }\end{array}$ & $\begin{array}{l}34,976 \text { PLWH, } 100 \% \text { male, } \\
\text { mean age } 39.8 \text { years, } 72.15 \% \\
\text { on PI based ART }\end{array}$ & $\begin{array}{l}\text { Fatal and non-fatal } \mathrm{MI} \\
\text { (retrospectively by ICD } 9 / 10 \\
\text { coding and } \\
\text { questionnaires) }\end{array}$ & $\begin{array}{l}\text { Incidence rate }(95 \% \mathrm{Cl}) \text { per } 10,000 \mathrm{PY} \text { in patients exposed to } \mathrm{PI} \\
\text { for: } 18 \text { months } 8.2(4.7,11.7) ; 18-29 \text { months } 15.9(7.9,23.9) \text {; } \\
>30 \text { months } 33.8(15.4,52.1) \text {. }\end{array}$ & 107 \\
\hline 2015 & Paisible AL et al. & $\begin{array}{l}\text { Veterans Ageing Cohort } \\
\text { Study, USA }\end{array}$ & $\begin{array}{l}26,836 \text { PLWH, mean (SD) age } \\
46 \text { (10) years, } 89.5 \% \text { male, } \\
50.75 \% \text { on ART }\end{array}$ & $\begin{array}{l}\text { Acute MI (adjudicated VA data, } \\
\text { ICD-9 coding and death } \\
\text { certification) }\end{array}$ & $\begin{array}{l}\text { Higher incidence rate of AMI in PLWH with the same CVD risk } \\
\text { profile. In those with no major CVD risk, HIV infection was } \\
\text { associated with twice the risk of AMI [hazard ratio (HR) }(95 \% \mathrm{Cl}) \\
2(1.0,3.9)] \text {. }\end{array}$ & 3 \\
\hline 2018 & Shah ASV et al. & $\begin{array}{lll}\begin{array}{l}\text { Meta-analysis across } 80 \\
\text { studies }\end{array} & \\
\end{array}$ & $\begin{array}{l}\text { 793,635 PLWH with a follow up } \\
\text { of } 3.5 \text { million PY }\end{array}$ & Fatal or non-fatal MI or stroke & $\begin{array}{l}\text { Crude incidence rate }(95 \% \mathrm{Cl}) \text { per } 10,000 \text { years for CVD was } 61.6 \\
(45.8,83.4) \text {. }\end{array}$ & 5 \\
\hline 1999 & Silverberg MJ et al. & 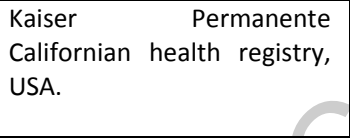 & $\begin{array}{l}22,081 \text { PLWH, } 90.6 \% \text { male, } \\
54.7 \% 35-49 \text { years, } 79.8 \% \text { ART } \\
\text { experienced at end of study } \\
\text { period }\end{array}$ & $\begin{array}{l}\text { MI (ICD-9 Inpatient discharge } \\
\text { coding) }\end{array}$ & $\begin{array}{l}\text { Incidence rate of MI per 100,000 PY: PLWH } 283 \text {, HIV negative } \\
165 . \mathrm{RR}(95 \% \mathrm{Cl}) \text { for HIV status was } 1.72(1.51,1.94) \text { unadjusted } \\
\text { and } 1.44(1.27,1.64) \text { adjusted. }\end{array}$ & 4 \\
\hline 2007 & Triant VA et al. & $\begin{array}{l}\text { Partners Healthcare System } \\
\text { registry, Boston, USA }\end{array}$ & $\begin{array}{l}3,851 \text { PLWH, } 69.6 \% \text { male, } \\
\text { median (interquartile range) } \\
\text { age } 38(32,44) \text { years, } 63.1 \% \text { on } \\
\text { PI-based ART }\end{array}$ & $\begin{array}{l}\text { Acute } \mathrm{MI} \text { (retrospectively ICD } \\
\text { 9/10 coding) }\end{array}$ & $\begin{array}{l}\text { Incidence rate }(95 \% \mathrm{Cl}) \text { per } 1,000 \text { PY: PLWH } 11.3(9.58,12.68) \text {, } \\
\text { HIV negative } 6.98(6.89,7.06) \text {. Adjusted RR }(95 \% \mathrm{Cl}) \text { of AMI in } \\
\text { PLWH: } 1.75(1.51,2.02) .\end{array}$ & 31 \\
\hline
\end{tabular}

